Résumés des conférences et travaux

\title{
Langues et littératures celtiques
}

\section{Pierre-Yves Lambert}

\section{(2) OpenEdition \\ Journals}

Édition électronique

URL : https://journals.openedition.org/ashp/2018

DOI : $10.4000 /$ ashp. 2018

ISSN : 1969-6310

Éditeur

Publications de l'École Pratique des Hautes Études

\section{Édition imprimée}

Date de publication : 1 septembre 2017

Pagination : 433-434

ISSN : 0766-0677

\section{Référence électronique}

Pierre-Yves Lambert, "Langues et littératures celtiques », Annuaire de l'École pratique des hautes études (EPHE), Section des sciences historiques et philologiques [En ligne], 148 | 2017, mis en ligne le 04 octobre 2017, consulté le 06 juillet 2021. URL : http://journals.openedition.org/ashp/2018 ; DOI : https:// doi.org/10.4000/ashp.2018 


\title{
LANGUES ET LITTÉRATURES CELTIQUES
}

\author{
Directeur d'études : M. Pierre-Yves LAMberT
}

Programme de l'année 2015-2016 : I. Irlandais ancien, gloses en vieil-irlandais; le Saltair na Rann, un poème biblique en moyen-irlandais. - II. Gallois moyen, Math vab Mathonwy, la "quatrième branche du Mabinogi ».

En introduction au vieil-irlandais, le directeur d'études a proposé aux auditeurs la lecture de gloses tirées du manuscrit de Milan, Ambrosianus C 301 Inf., portant sur le Psautier. On a lu les gloses se rapportant au psaume 14, c'est-à-dire les gloses 35 b 23 à 36 b 14 (p. 85-90 de l'édition de Stokes et Strachan).

Le texte principal mis au programme cette année était le Saltair na Rann, littéralement «psautier des strophes », c'est-à-dire le " psautier en vers », une œuvre du début du moyen-irlandais (un passage énumérant les rois et seigneurs contemporains permet de dater l'ouvrage de 987). L'ouvrage est attribué à Oengus Céile Dé (c'està-dire à un membre du mouvement de réforme des Céili Dé), mais cette attribution a été contestée. Divisé en cent-cinquante « chants », le poème s'est donné pour mission de raconter les principaux épisodes de l'Ancien Testament. On a pu constater l'introduction de thèmes apocryphes, notamment dans l'histoire d'Adam et Ève, ou dans l'histoire de Moïse. Le directeur d'études a expliqué principalement l'histoire de Noé, de la Tour de Babel, et le début de l'histoire de Jacob et de celle de Joseph. Il a fallu mettre à contribution de nombreuses études comme celles de Kuno Meyer, qui a particulièrement étudié la métrique (dans le mètre deibide). L'édition de Whitley Stokes, parue en 1890, est une simple transcription du texte d'après le manuscrit unique, Rawlinson B 502 (heureusement disponible en ligne). Il n'existe de traduction imprimée que pour l'histoire d'Adam et Ève et quelques autres passages; mais la School of Celtic Studies de Dublin (Dublin Institute for Advanced Studies) a mis à la disposition des chercheurs un projet de traduction dû à la plume de David Greene, accompagné d'un texte édité, que nous avons pu discuter durant la conférence. L'intérêt principal du texte est certainement de montrer quels étaient les passages favoris des Irlandais dans la Bible, et comment ces lectures étaient comprises. On trouve aussi des informations précieuses sur le début du moyen-irlandais, avec un commencement de simplification du système verbal.

En fin d'année, on s'est intéressé à un état de langue plus récent, celui de la version en prose du Saltair na Rann. Cette version en prose est disponible dans plusieurs manuscrits; on a lu la version du Leabhar Breac (d'après le Facsimile, p. 113-115) pour l'histoire de Jacob et celle de Joseph. Cette version en prose mélange des formes de moyen-irlandais et d'irlandais moderne (avec de nombreux exemples du pronom indépendant objet).

Le texte gallois moyen mis au programme était un texte en prose, Math uab Mathonwy, ou « La quatrième branche du Mabinogi ». Ce texte, probablement composé au XII ${ }^{\mathrm{e}}$ siècle, a suscité l'intérêt de Georges Dumézil et des comparatistes des 
religions. Nous avons profité aussi des dernières études consacrées à ce texte, par Ian Hughes, tout comme des travaux célèbres de W. J. Gruffydd, qui avaient suscité les critiques de Joseph Loth.

Monsieur Hervé Le Bihan, professeur à Rennes-II, a eu l'obligeance de venir faire plusieurs conférences sur des textes en moyen-breton : notamment le dialogue d'Arthur et Guinglaff, la vie de sainte Nonne. Ces conférences apportent un complément tout à fait bienvenu à nos conférences de celtique, elles ont beaucoup intéressé les auditeurs.

Le directeur d'études a entretenu ses auditeurs des recherches en cours : les nouvelles inscriptions gauloises (Lezoux), les nouvelles gloses en vieux-breton, les derniers développements dans la recherche sur les gloses en vieil-irlandais, en vieux-gallois et en vieux-breton. On a discuté de questions étymologiques (surtout à propos de vieil-irlandais). 